\title{
Personality Traits as Predictors of Decline in Higher-Level Functional Capacity over a 7-Year Follow-Up in Older Adults: The Ohasama Study
}

\author{
Megumi Tsubota-Utsugi, ${ }^{1,2}$ Michihiro Satoh, ${ }^{3}$ Miki Hosaka, ${ }^{4}$ Ryusuke Inoue, ${ }^{5}$ \\ Kei Asayama, ${ }^{4,6}$ Takuo Hirose, ${ }^{7}$ Hirohito Metoki, ${ }^{8}$ Masahiro Kikuya, ${ }^{8}$ Yutaka Imai ${ }^{4}$ \\ and Takayoshi Ohkubo ${ }^{6}$

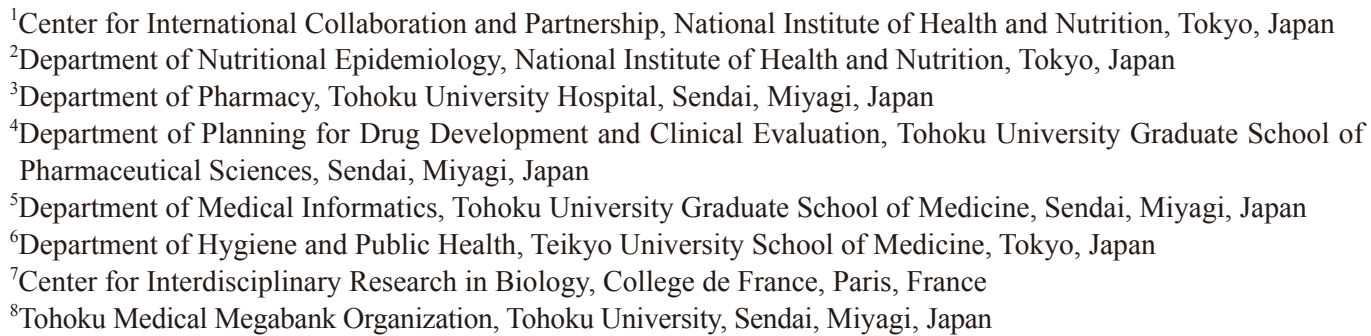

Numerous factors that affect functional decline have been identified, and personality traits are considered to be an important factor in functional decline risk. The Tokyo Metropolitan Institute of Gerontology Index of Competence (TMIG) was developed to measure three higher-level functional capacities, instrumental activities of daily living, intellectual activity, and social roles, in Japanese elderly, which were previously not assessed adequately with existing scales of functional decline. The objective of this study was to explore the effect of personality traits as predictors of higher-level functional decline over a 7-year follow-up in a rural Japanese community. Data on 676 participants (mean 67.1 years) who were free of functional decline and had completed questionnaires at baseline and 7 years later, were analyzed. Demographic characteristics, lifestyle and personality characteristics were obtained from a self-administered questionnaire at baseline. Higher-level functional decline was examined using the subscales of the TMIG at baseline and at a 7 -year follow-up examination. Over the 7 -year study period, $21.7 \%$ of eligible participants reported decline in higher-level functional capacity. After adjustment for putative confounding factors, the traits that were significant predictors of decline in higher-level functional capacity at the 7-year follow-up had higher psychoticism scores [odds ratio (95\% confidence interval) 2.12 (1.23-3.66)] and lower extraversion scores [1.89 (1.01-3.56)]. The personality traits of higher psychoticism and lower extraversion were significantly associated with a risk of future functional decline. A better understanding of these personality traits may help identify of at-risk individuals and could help reduce functional decline in older adults.

Keywords: extraversion; higher-level functional decline; Japanese residents; lifestyle; psychoticism Tohoku J. Exp. Med., 2014 November, 234 (3), 197-207. C 2014 Tohoku University Medical Press

\section{Introduction}

With the rapidly increasing life expectancy of the Japanese population (Ministry of Health, Labour and Welfare 2008), elderly health constitutes an important public health concern in terms of mortality, morbidity, social health care costs, and longevity with quality of life. Functional decline is now considered to have an enormous effect on hospitalization, institutionalization, and death, and to adversely affect the Japanese economy (Ministry of Health, Labour and Welfare 2005). Therefore, identifying risk factors and preventing causes of functional decline in elderly persons at an early stage is imperative.

A hierarchical model of functional and behavioral competence has been defined and organized into seven stages by Lawton: life maintenance, functional health, perception and cognition, physical self-maintenance, instrumental self-maintenance [corresponding to instrumental

Received May 23, 2014; revised and accepted September 30, 2014. Published online October 23, 2014; doi: 10.1620/tjem.234.197.

Correspondence: Megumi Tsubota-Utsugi, Center for International Collaboration and Partnership, and Department of Nutritional

Epidemiology, National Institute of Health and Nutrition, Toyama 1-23-1, Shinjyuku-ku, Tokyo 162-8636, Japan.

e-mail: mutsugky@nih.go.jp 
activities of daily living (IADL)], intellectual activity (effectance), and social role performance (Lawton and Brody 1969; Lawton 1972). Impairment at any sublevel is more likely to impair the higher levels. Higher-level functional capacity encompasses the complex abilities in Lawton's last three stages (instrumental self-maintenance, intellectual activity, and social role performance), and the scale to assess these stages has been developed in Japan (Koyano et al. 1987, 1991, 1993). This new index may identify risk factors and preventable causes of functional decline at an earlier stage compared to other existing scales.

Numerous factors that affect functional decline have been identified using a new index (Koyano et al. 1987, 1991, 1993), and we revealed significant associations between health behaviors and risk of decline in higher-level functional capacity (Tsubota-Utsugi et al. 2011; Imai et al. 2014). Personality traits are also considered to be an important factor in functional decline risk. Several studies have reported that personality traits such as neuroticism, extraversion, anger, and hostility are significant predictors of mortality, and clinical health outcomes (Almada et al. 1991; Wilson et al. 2005; Hozawa et al. 2006; Shipley et al. 2007). Particularly in elderly populations, it has been hypothesized that these traits may affect subsequent physical health outcomes and mortality (Duberstein et al. 2003; Wilson et al. 2005; Krueger et al. 2006; Hampson et al. 2007). However, there have been few prospective studies of the association between personality traits and functional decline, and no studies have examined the risk factors related to loss of higher-level functional capacity. Because there are geographical, regional, and cultural differences in risk factors of functional decline among countries (Fujiwara et al. 2000; Kaneki et al. 2001; Amorim-Cruz et al. 2002; Fujiwara et al. 2003c), a better understanding of personality trait risk factors is also a high priority to prevent future deterioration in activities of daily living (ADLs) (Tinetti et al. 1995; Fujiwara et al. 2003a).

The aims of this study were to clarify the associations between the personalities of individuals, as measured by the Japanese version of the short-form Eysenck personality questionnaire (short EPQ-R) (Eysenck et al. 1985; Hosokawa and Ohyama 1993), and to study future decline in higher-level functional capacity in older communitydwelling adults in a Japanese general population based on 7 years of follow-up data.

\section{Methods}

Ohasama Study

The present study is a part of the Ohasama Study, a longitudinal community-based observational study of individuals who have participated in a home blood pressure measurement project in Ohasama, Iwate prefecture, Japan. The geographic and demographic characteristics of study subjects have been described previously (Tsuji et al. 1997; Ohkubo et al. 2006).

This study was approved by the Institutional Review Board of Tohoku University School of Medicine and by the Department of
Health of the Ohasama Town Government. Written informed consent was obtained from all subjects.

Subjects for the present study

The total population aged 60 years or over was 2,614 in 1998. Of this, 2,348 subjects (response rate $89.8 \%$ ) participated in the study from February 1 through March 28, 1998. A total of 1,015 subjects were excluded from the follow-up measurement for the following reasons: incomplete answers to the questionnaire for the EPQ-R, the Tokyo Metropolitan Institute of Gerontology Index of Competence (TMIG), and the six-item physical function measurement of the Medical Outcomes Study short-form General Health Survey (MOS) at baseline $(n=372)$; not fully independent at baseline ADL (person's basic activity or movement in daily life, which is often used in assessing functional ability of the elderly, but not include cognitive ability) [<1 point for the MOS $(n=334)$ (Stewart et al. 1988, 1989; Tsuji et al. 1999)]; or low level of higher-level functional capacity $[<10$ points for the 13-item TMIG-index] $(n=309)$. Among these participants, 839 (62.9\%) answered all 48 items of the short EPQ-R. Table 1 compares the characteristics of participants who did and did not complete all 48 items of the short EPQ-R. Participants who completed the short EPQ-R were younger, and more likely to be current smokers, current drinkers, breakfast eaters, eating out, and a higher body mass index (BMI). The follow-up study was conducted during the period from April 8 to May 20, 2005. Of the remaining 839 eligible individuals in the follow-up study, 163 subjects were excluded because they died $(n=80)$, moved away from town $(n=17)$, or did not agree to participate in the follow-up study $(n=66)$. Finally, data from 676 subjects ( $40.9 \%$ men; mean age, 67.5 years) were analyzed.

Table 2 compares the general characteristics of participants and non-participants in the follow-up study. Participants were younger age, lower prevalence of hypertension, stroke, myocardial infarction, and hearing impairment, and subjects reporting excellent self-rated health.

\section{Data collection}

Personality assessment: The Japanese version of the short EPQ$\mathrm{R}$, one of the personality inventories developed by Eysenck and colleagues (1985), consists of 48 questions with dichotomized responses (yes or no). There are 12 questions for each of the four personality subscales: extraversion, neuroticism, psychoticism, and lie. The validity and reliability of the Japanese version of the short EPQ-R has been confirmed (Hosokawa and Ohyama 1993). Scores on each subscale range from 0 to 12 , with higher scores indicating a greater tendency of possession of the personality trait represented by each subscale. In general, extraversion is characterized by sociability, liveliness, and activity; neuroticism is characterized by emotional instability and anxiousness; psychoticism is characterized by toughmindedness, aggressiveness, coldness, and egocentricity; and lie is characterized by the tendency to 'fake good' or social desirability and social naivety or conformity. Subjects were divided into quartiles according to their scores for each trait, and the highest quartile was used as the reference category for extraversion and the lowest quartile was used as the reference category for psychoticism, neuroticism, and lie.

Higher-level functional capacity: Higher-level functional capacity was measured using the TMIG-index (Koyano et al. 1987, 1991, 1993; Fujiwara et al. 2003a). This measure is made up of three subscales: social role, intellectual activity, and instrumental activities of 
Table 1. Character differences between those who did and did not complete all 48 items of the short EPQ-R in the Ohasama Study, Japan, 1998.

\begin{tabular}{|c|c|c|c|c|}
\hline & & $\begin{array}{l}\text { Those who incomplete } \\
\text { all items }\end{array}$ & $\begin{array}{l}\text { Those who complete } \\
\text { all items }\end{array}$ & $P$ value $^{\mathrm{a}}$ \\
\hline Number of subjects & & 494 & 839 & \\
\hline Age in years, mean ( \pm standard deviation & & $69.2(6.4)$ & $68.0(6.0)$ & $<.001$ \\
\hline Male, $\%$ & & 37.3 & 46.0 & $<.001$ \\
\hline Married, \% & & 92.7 & 87.7 & $<.001$ \\
\hline Living alone, \% & & 8.5 & 8.9 & 0.785 \\
\hline Educational attainment, $<10$ years, $\%$ & & 86.0 & 78.0 & $<.001$ \\
\hline Current job, \% & & 81.2 & 88.1 & $<.001$ \\
\hline \multicolumn{5}{|l|}{ Smoking behavior, $\%$} \\
\hline & Never & 72.1 & 65.1 & 0.030 \\
\hline & Former smoker & 12.8 & 16.5 & \\
\hline & Current & 15.2 & 18.5 & \\
\hline \multicolumn{5}{|l|}{ Alcohol consumption, \% } \\
\hline & Never & 64.4 & 53.4 & $<.001$ \\
\hline & Former drinker & 4.7 & 6.2 & \\
\hline & Current & 31.0 & 40.4 & \\
\hline \multicolumn{5}{|l|}{ Frequency of exercise, $\%$} \\
\hline & Rarely or never & 73.7 & 72.6 & 0.269 \\
\hline & 1 or 2 hour(s)/week & 16.0 & 17.6 & \\
\hline & 3 hours/week & 10.3 & 9.8 & \\
\hline \multicolumn{5}{|l|}{ Sleep duration, \% } \\
\hline & Short time, $<7$ hours/day & 23.5 & 18.0 & $<.001$ \\
\hline & $\geq 7$ and $<9$ hours/day & 56.1 & 64.5 & \\
\hline & Long time, $\geq 9$ hours/day & 20.5 & 17.5 & \\
\hline Self-rated health, excellent $\%$ & & 71.5 & 71.2 & 0.907 \\
\hline \multicolumn{5}{|l|}{ Dietary habits } \\
\hline & Supplements use, $\%$ & 28.3 & 26.8 & 0.547 \\
\hline & Breakfast, \% & 92.3 & 95.5 & 0.016 \\
\hline & Late-night snack, $\geq 1$ time(s)/week \% & 21.7 & 16.1 & 0.011 \\
\hline & Eating regularly, $\%$ & 90.1 & 92.6 & 0.107 \\
\hline & Eating out, $\geq 1$ time(s)/week $\%$ & 10.7 & 16.7 & $<.001$ \\
\hline \multicolumn{5}{|l|}{ Past history, \% } \\
\hline & Hypertension & 44.1 & 46.7 & 0.359 \\
\hline & Hypercholesterolemia & 14.2 & 16.1 & 0.348 \\
\hline & Diabetes & 12.8 & 12.8 & 1.000 \\
\hline & Stroke & 2.4 & 3.0 & 0.555 \\
\hline & Myocardial infarction & 8.5 & 12.0 & 0.044 \\
\hline & Cancer & 4.3 & 3.0 & 0.219 \\
\hline & Hearing impairment & 5.9 & 11.0 & $<.001$ \\
\hline & Cataract & 24.1 & 23.4 & 0.763 \\
\hline & Inflammation of the joint & 14.6 & 12.8 & 0.346 \\
\hline & Osteoporosis & 6.9 & 7.3 & 0.790 \\
\hline \multicolumn{5}{|l|}{ Body Mass Index in $\mathrm{kg} / \mathrm{m}^{2}, \%$} \\
\hline & Underweight, $<18.5$ & 13.0 & 5.8 & $<.001$ \\
\hline & Normal, $\geq 18.5$ and $<25.0$ & 60.5 & 64.7 & \\
\hline & Overweight, $\geq 25.0$ & 26.5 & 29.4 & \\
\hline
\end{tabular}

The short EPQ-R, the short-form Eysenck personality questionnaire.

${ }^{a}$ Obtained by $t$ test or Wilcoxon signed rank test for continuous variables and chi-squared test for categorical variables, comparing respondents and non-respondents groups. 
M. Tsubota-Utsugi et al.

Table 2. Characteristics between participants and non participants at baseline in the Ohasama Study, Japan, 1998.

\begin{tabular}{|c|c|c|c|c|c|c|}
\hline & \multirow[b]{2}{*}{ Participants } & \multicolumn{3}{|c|}{ Non participants } & \multirow[b]{2}{*}{$P$ value $^{\mathrm{a}}$} & \multirow[b]{2}{*}{$P$ value $^{\mathrm{b}}$} \\
\hline & & Died & Moved & $\begin{array}{l}\text { Unwilling to } \\
\text { participate }\end{array}$ & & \\
\hline Number of subjects & 676 & 80 & 17 & 66 & & \\
\hline Age in years, mean ( \pm s.D.) & $67.1(5.5)$ & $71.7(6.6)$ & $68.7(7.9)$ & $71.9(6.5)$ & $<.001$ & $<.001$ \\
\hline Male, $\%$ & 42.6 & 80.0 & 47.1 & 39.4 & $<.001$ & $<.001$ \\
\hline Married, \% & 88.6 & 85.0 & 82.4 & 83.3 & 0.111 & 0.444 \\
\hline Living alone, $\%$ & 7.8 & 11.3 & 11.8 & 16.7 & 0.023 & 0.088 \\
\hline Educational attainment, $<10$ years, $\%$ & 78.1 & 76.3 & 76.5 & 78.8 & 0.830 & 0.979 \\
\hline Current job, $\%$ & 88.0 & 87.5 & 88.2 & 89.4 & 0.908 & 0.987 \\
\hline \multicolumn{7}{|l|}{ Smoking behavior, $\%$} \\
\hline Never & 68.2 & 37.5 & 67.4 & 66.7 & 0.001 & $<.001$ \\
\hline Former smoker & 14.8 & 28.8 & 17.7 & 18.2 & & \\
\hline Current & 17.0 & 33.8 & 17.7 & 15.2 & & \\
\hline \multicolumn{7}{|l|}{ Alcohol consumption, $\%$} \\
\hline Never & 56.1 & 31.3 & 35.3 & 57.6 & 0.002 & $<.001$ \\
\hline Former drinker & 5.2 & 10.0 & 17.7 & 9.1 & & \\
\hline Current & 38.8 & 58.8 & 47.1 & 33.3 & & \\
\hline \multicolumn{7}{|l|}{ Frequency of exercise, $\%$} \\
\hline Rarely or never & 72.8 & 65.0 & 88.2 & 75.8 & 0.269 & 0.196 \\
\hline 1 or 2 hour(s)/week & 18.2 & 18.8 & 0.0 & 15.2 & & \\
\hline 3 hours/week & 9.0 & 16.3 & 11.8 & 9.1 & & \\
\hline \multicolumn{7}{|l|}{ Sleep duration, $\%$} \\
\hline Short time, $<7$ hours/day & 18.2 & 11.3 & 17.7 & 24.2 & 0.001 & $<.001$ \\
\hline$\geq 7$ and $<9$ hours/day & 66.7 & 60.0 & 64.7 & 47.0 & & \\
\hline Long time, $\geq 9$ hours/day & 15.1 & 28.8 & 17.7 & 28.8 & & \\
\hline Self-rated health, excellent $\%$ & 73.1 & 62.5 & 58.8 & 65.2 & 0.012 & 0.088 \\
\hline \multicolumn{7}{|l|}{ Dietary habits } \\
\hline Supplements use, $\%$ & 27.2 & 22.5 & 29.4 & 27.3 & 0.593 & 0.830 \\
\hline Breakfast, $\%$ & 96.2 & 91.3 & 82.4 & 97.0 & 0.053 & 0.011 \\
\hline Late-night snack, $\geq 1$ time(s)/week $\%$ & 16.7 & 8.8 & 17.7 & 18.2 & 0.315 & 0.304 \\
\hline Eating regularly, $\%$ & 92.8 & 92.5 & 82.4 & 93.9 & 0.750 & 0.423 \\
\hline Eating out, $\geq 1$ time(s)/week $\%$ & 16.4 & 21.3 & 23.5 & 12.1 & 0.673 & 0.424 \\
\hline \multicolumn{7}{|l|}{ Past history, $\%$} \\
\hline Hypertension & 44.5 & 61.3 & 70.6 & 45.5 & 0.009 & $<.001$ \\
\hline Hypercholesterolemia & 16.6 & 13.8 & 23.5 & 12.1 & 0.443 & 0.592 \\
\hline Diabetes & 12.7 & 15.0 & 23.5 & 7.6 & 0.956 & 0.292 \\
\hline Stroke & 2.2 & 8.8 & 0.0 & 4.6 & 0.008 & $<.001$ \\
\hline Myocardial infarction & 10.5 & 12.5 & 41.2 & 19.7 & 0.005 & $<.001$ \\
\hline Cancer & 2.8 & 3.8 & 11.8 & 1.5 & 0.558 & 0.154 \\
\hline Hearing impairment & 9.6 & 22.5 & 11.8 & 10.6 & 0.011 & $<.001$ \\
\hline Cataract & 22.5 & 23.8 & 23.5 & 31.8 & 0.222 & 0.402 \\
\hline Inflammation of the joint & 12.0 & 17.5 & 11.8 & 15.2 & 0.173 & 0.505 \\
\hline Osteoporosis & 7.4 & 5.0 & 11.8 & 7.6 & 0.775 & 0.766 \\
\hline \multicolumn{7}{|l|}{ Body Mass Index in $\mathrm{kg} / \mathrm{m}^{2}, \%$} \\
\hline Underweight, $<18.5$ & 5.2 & 8.8 & 0.0 & 10.6 & 0.220 & 0.357 \\
\hline Normal, $\geq 18.5$ and $<25.0$ & 64.8 & 62.5 & 64.7 & 66.7 & & \\
\hline Overweight, $\geq 25.0$ & 30.0 & 28.8 & 35.3 & 22.7 & & \\
\hline Total score of the TMIG & $12.4(0.9)$ & $12.3(1.0)$ & $12.0(1.1)$ & $12.1(1.1)$ & 0.005 & 0.015 \\
\hline IADL & $5.0(0.2)$ & $4.9(0.4)$ & $4.9(0.3)$ & $4.9(0.3)$ & $<.001$ & $<.001$ \\
\hline Intellectual activity & $3.6(0.7)$ & $3.7(0.7)$ & $3.4(0.9)$ & $3.5(0.7)$ & 0.683 & 0.420 \\
\hline Social role & $3.8(0.5)$ & $3.8(0.6)$ & $3.7(0.6)$ & $3.7(0.6)$ & 0.011 & 0.065 \\
\hline
\end{tabular}

S.D., Standard Deviation; TMIG, the Tokyo Metropolitan Institute of Gerontology Index of Competence; IADL, instrumental activity of daily living.

aObtained by $t$ test or Wilcoxon signed rank test for continuous variables and chi-squared test for categorical variables, comparing participants and non-participants groups.

${ }^{b}$ Obtained by one-way analysis of variance for continuous variables and chi-squared test for categorical variables, comparing participants, died, moved, and unwilling to participate groups. 
daily living (IADL). Social role, defined as levels of adequacy in roles such as spouse, parent, informal social group, and intellectual activity, and adapted from Lawton's "effectance," is the motivation behind the human need to create tension, to explore, and to vary the psycho-environmental field, e.g., taking interest in health-related information through the mass media (Lawton and Brody 1969; Lawton 1972). Each item was scored 1 for "yes (able to do)" or 0 for "no (unable to do)." The total score was the sum of scores for the 13 items with a higher total score indicating a higher-level of competence. The validity and reliability of the TMIG questionnaire have been established (Koyano et al. 1991), and the high predictive validity was previously confirmed using 1-year mortality as a criterion variable (Koyano et al. 1991; Koyano and Shibata 1992). The TMIGindex has been widely used in Japan (Koyano et al. 1991; Fujiwara et al. 2003b, c; Kwon et al. 2006).

Changes in higher-level functional capacity during the 7-year period were calculated by subtracting the sum of TMIG scores in 1998 from those in 2005. Thereafter, the subjects were classified into two groups: "decline (TMIG change $<-1$ )" and "no decline (stable or improved) (TMIG change $\geq-1$ )." This cut-off point was used because a previous study reported that variations of 1 point in the total score of the TMIG-index, subscales of intellectual activity, and social role were within the range of possible measurement error (Fujiwara et al. 2003a). Three subscales of competence were also calculated, and subjects were divided into two groups by each subscale as stated above: "decline $(<-1)$ " and "no decline $(\geq-1)$ " for intellectual activity and social role, and "decline $(<0)$ " and "no decline ( $\geq 0$ )" for IADL (Fujiwara et al. 2003a).

Other demographic and lifestyle characteristics: Information on other demographic and lifestyle characteristics was obtained by a questionnaire in 1998. Smoking behavior were classified as "never," "former smoker," or "current smoker." Alcohol consumption was classified as "never," "former drinker," or "current drinker." With regards to frequency of exercise, subjects were categorized according to their answer to the question, "How many times do you normally exercise per week?" The responses were divided into three groups by the frequency of exercise: "rarely or never $(<1 \mathrm{~h} /$ week)," "1 or $2 \mathrm{~h} /$ week," or " $\geq 3 \mathrm{~h} /$ week." Sleep duration was classified as "short time ( $<7$ hours/day)," " $\geq 7$ and $<9$ hours/day," or "long time ( $\geq 9$ hours/ day)." Questions about the following dietary habits were also asked: taking supplements (yes/no), having breakfast (yes/no), eating regularly (yes/no), having late-night snacks [yes ( $\geq 1$ time(s)/week)/no], and eating out [yes $(\geq 1$ time(s)/week)/no].

Self-reported body weight and height were used to calculate BMI, which was classified as underweight $\left(<18.5 \mathrm{~kg} / \mathrm{m}^{2}\right)$, normal weight $\left(\geq 18.5\right.$ and $\left.<25.0 \mathrm{~kg} / \mathrm{m}^{2}\right)$, or overweight $\left(\geq 25.0 \mathrm{~kg} / \mathrm{m}^{2}\right)$. Other characteristics, including sex (male/female), age (continuous), current marital status (which did not include persons who were bereaved or separated) (yes/no), living alone (yes/no), educational attainment ( $<10$ years $/ \geq 10$ years), self-rated health (excellent, good/ fair, or poor), current job (yes/no), and past history of hypertension, hypercholesterolemia, diabetes, stroke, myocardial infarction, cancer, hearing impairment, cataract, joint inflammation, and osteoporosis (yes/no), were also taken into account.

\section{Statistical analyses}

To explore the associations between total scores and subscale scores of higher-level functional decline and each personality trait, we used a multiple logistic regression model by quartiles for each personality trait and a multiple linear regression model for continuous analysis of each personality trait with adjustments for other putative confounding variables. A two-step process was used to determine the best model for the study. To examine how each variable independently affected the odds ratios, we first selected variables on the basis of plausibility and previous literature. Then, we used univariate logistic regression analysis to determine the associations of all variables added separately with TMIG change in the present study. Subsequently, all variables with a univariate test $P$ value $\leq 0.10$ were considered for inclusion for adjustment in the multiple logistic regression models. The combined effect of all personality traits in the EPQ-R on total scores and subscale scores of higher-level functional decline were also examined. Moreover, the stratified analysis was performed according to lifestyle factors, i.e., overweight (BMI $=25$ $\mathrm{kg} / \mathrm{m}^{2}$ as cutoff), frequency of exercise ( $\geq 1 \mathrm{~h} /$ week or rarely or never), smoking status (never or ex-/current smoker), alcohol consumption (never or ex-/current drinker), self-rated health (excellent, good, or fair/poor), and frequency of eating out [yes ( $\geq 1$ time(s)/ week)/no], to explore the effect of these factors. Possible interactions were tested by introducing a multiplicative term into the main effect models. For all analyses, the level of statistical significance was set at two-tailed $P<0.05$. All statistical analyses were performed using SAS software, version 9.3 (SAS Institute Inc., Cary, NC, USA).

\section{Results}

During the 7-year follow-up period, the following percentages of subjects reported a decline in higher-level functional capacities: total TMIG score, $21.7 \%(n=147)$; IADL, $18.2 \%(n=123)$; intellectual activity, $9.0 \%(n=61)$; and social role, $9.5 \%(n=64)$. The mean scores (s.D.) on the short EPQ-R for our participants were 3.1 (1.7) for psychoticism, 6.5 (2.9) for extraversion, and 5.4 (3.1) for neuroticism. These values are consistent with those reported for the general population (Hosokawa and Ohyama 1993). There were no differences in any type of higher-level functional decline between men and women.

The distributions of general characteristics across quartiles of each personality trait at baseline are shown in Table 3. Subjects in the highest quartile of extraversion were more likely to be current smokers, having higher frequencies of exercise ( $>3 \mathrm{~h} /$ week), longer sleep duration, excellent self-rated health, eating regularly, having a lower frequency of supplement use, and having lower total TMIG and social role subscale scores. Compared with those in the lowest quartile of psychoticism, those in the highest quartile were more likely to be male, current smokers, heavier drinkers, having a higher frequency of skipping breakfast; and having lower total TMIG and social role subscale scores. Those in the highest quartile of neuroticism were poor self-rated health and higher frequency of supplement use.

Table 4 shows the association between each personality trait and total and subscale scores of higher-level functional decline. Age, educational attainment, past history of hypercholesterolemia and hearing impairment, sleep duration, frequency of eating out, and BMI were included as putative confounding factors because of univariate test $P$ 
Table 3. Characteristics of the study subjects according to the highest and lowest of quartile of each personality in the Ohasama Study, Japan, $1998(n=676)$.

\begin{tabular}{|c|c|c|c|c|c|c|c|c|c|c|c|c|}
\hline \multirow{3}{*}{ Characteristic of personality } & \multicolumn{3}{|c|}{ Extraversion } & \multicolumn{3}{|c|}{ Psychoticism } & \multicolumn{3}{|c|}{ Neuroticism } & \multicolumn{3}{|c|}{ Lie } \\
\hline & $\begin{array}{c}\mathrm{Q} 1 \\
\text { (lowest) }\end{array}$ & $\begin{array}{c}\text { Q4 } \\
\text { (highest) }\end{array}$ & \multirow{2}{*}{$\begin{array}{c}P \\
\text { value }^{\mathrm{a}}\end{array}$} & $\begin{array}{c}\mathrm{Q} 1 \\
\text { (lowest) }\end{array}$ & $\begin{array}{c}\text { Q4 } \\
\text { (highest) }\end{array}$ & \multirow{2}{*}{$\begin{array}{c}P \\
\text { value }^{\mathrm{a}}\end{array}$} & $\begin{array}{c}\mathrm{Q} 1 \\
\text { (lowest) }\end{array}$ & $\begin{array}{c}\text { Q4 } \\
\text { (highest) }\end{array}$ & \multirow{2}{*}{$\begin{array}{c}P \\
\text { value }^{\mathrm{a}}\end{array}$} & $\begin{array}{c}\mathrm{Q} 1 \\
\text { (lowest) }\end{array}$ & $\begin{array}{c}\text { Q4 } \\
\text { (highest) }\end{array}$ & \multirow{2}{*}{$\begin{array}{c}P \\
\text { value }\end{array}$} \\
\hline & Introversion & Extraversion & & Socialization & Psychoticism & & Stability & Neuroticism & & low SDR & SDR & \\
\hline Personality trait score & $0-4$ & $10-12$ & & $0-2$ & $5-10$ & & $0-3$ & $9-12$ & & $0-6$ & $10-12$ & \\
\hline Number of participants & 188 & 124 & & 277 & 124 & & 200 & 132 & & 275 & 191 & \\
\hline Age in years, mean ( \pm S.D.) & $67.1(5.4)$ & $67.4(5.6)$ & 0.776 & $66.8(5.2)$ & $66.7(5.0)$ & 0.256 & & & & $65.8(5.0)$ & $68.8(6.0) \S$ & $<.001$ \\
\hline Male, $\%$ & 48.9 & 46.0 & 0.084 & 30.3 & 58.9 & $<.001$ & 47.0 & 37.1 & 0.264 & 54.6 & 33.8 & $<.001$ \\
\hline Married, \% & 88.3 & 91.9 & 0.446 & 86.6 & 93.6 & 0.195 & 91.0 & 85.6 & 0.107 & 87.8 & 89.8 & 0.382 \\
\hline Living alone, \% & 12.2 & 4.0 & 0.039 & 9.0 & 4.0 & 0.336 & 8.5 & 10.6 & 0.458 & 7.7 & 8.3 & 0.123 \\
\hline Educational attainment, $<10$ years, $\%$ & 76.6 & 79.8 & 0.062 & 78.7 & 78.2 & 0.858 & 72.0 & 81.1 & 0.029 & 74.2 & 80.9 & 0.372 \\
\hline Current job, $\%$ & 87.8 & 91.1 & 0.462 & 86.3 & 90.3 & 0.588 & 90.0 & 87.9 & 0.674 & 90.1 & 86.0 & 0.665 \\
\hline Smoking behavior, $\%$ & & & 0.012 & & & 0.005 & & & 0.756 & & & $<.001$ \\
\hline Never & 60.6 & 66.9 & & 73.7 & 58.1 & & 64.5 & 72.0 & & 55.7 & 74.5 & \\
\hline Former smoker & 22.3 & 10.5 & & 11.2 & 17.7 & & 16.0 & 14.4 & & 21.7 & 10.2 & \\
\hline Current & 17.0 & 22.6 & & 15.2 & 24.2 & & 19.5 & 13.6 & & 22.6 & 15.3 & \\
\hline Alcohol consumption, $\%$ & & & 0.095 & & & 0.001 & & & 0.379 & & & $<.001$ \\
\hline Never & 54.3 & 56.5 & & 66.1 & 46.0 & & 53.0 & 62.9 & & 42.5 & 65.0 & \\
\hline Former drinker & 8.5 & 1.6 & & 4.7 & 4.8 & & 6.5 & 5.3 & & 5.4 & 5.1 & \\
\hline Current & 37.2 & 41.9 & & 28.2 & 49.2 & & 40.5 & 31.8 & & 52.0 & 29.9 & \\
\hline Frequency of exercise, $\%$ & & & 0.022 & & & 0.217 & & & 0.800 & & & 0.840 \\
\hline Rarely or never & 76.1 & 61.3 & & 72.0 & 79.8 & & 72.5 & 73.5 & & 72.4 & 9.9 & \\
\hline 1 or 2 hour(s)/week & 16.5 & 24.2 & & 17.0 & 13.7 & & 19.0 & 16.7 & & 18.6 & 20.4 & \\
\hline 3 hours/week & 7.5 & 14.5 & & 10.8 & 6.5 & & 8.5 & 9.9 & & 9.1 & 10.8 & \\
\hline Sleep duration, $\%$ & & & 0.122 & & & 0.297 & & & 0.183 & & & 0.298 \\
\hline Short time, $<7$ hours/day & 17.6 & 14.5 & & 19.1 & 13.7 & & 14.0 & 22.0 & & 15.8 & 17.2 & \\
\hline$\geq 7$ and $<9$ hours/day & 67.6 & 66.1 & & 68.6 & 64.5 & & 74.5 & 61.4 & & 65.2 & 71.3 & \\
\hline Long time, $\geq 9$ hours/day & 14.9 & 19.4 & & 12.3 & 21.8 & & 11.5 & 16.7 & & 19.0 & 11.5 & \\
\hline Self-rated health, excellent $\%$ & 59.0 & 87.9 & $<.001$ & 71.3 & 72.6 & 0.713 & 81.0 & 61.4 & 0.001 & 73.3 & 78.3 & 0.182 \\
\hline \multicolumn{13}{|l|}{ Dietary habits } \\
\hline Supplements use, $\%$ & 34.0 & 22.6 & 0.020 & 28.9 & 31.5 & 0.141 & 22.0 & 37.1 & 0.017 & 27.6 & 26.8 & 0.499 \\
\hline Breakfast, $\%$ & 96.3 & 96.8 & 0.489 & 98.6 & 92.7 & 0.029 & 94.5 & 96.2 & 0.492 & 96.4 & 96.2 & 0.991 \\
\hline $\begin{array}{l}\text { Late-night snack, } \\
\geq 1 \text { time(s)/week } \%\end{array}$ & 14.9 & 18.6 & 0.675 & 83.0 & 83.9 & 0.399 & 14.0 & 21.2 & 0.394 & 20.4 & 13.4 & 0.158 \\
\hline Eating regularly, $\%$ & 90.4 & 95.2 & 0.007 & 93.1 & 90.3 & 0.358 & 95.5 & 90.9 & 0.342 & 90.5 & 95.5 & 0.310 \\
\hline Eating out, $\geq 1$ time $(\mathrm{s}) /$ week $\%$ & 14.9 & 17.7 & 0.517 & 14.1 & 18.6 & 0.247 & 18.0 & 14.4 & 0.579 & 19.0 & 14.0 & 0.608 \\
\hline \multicolumn{13}{|l|}{ Past history, \% } \\
\hline Hypertension & 51.1 & 37.9 & 0.126 & 46.2 & 38.7 & 0.450 & 40.5 & 46.2 & 0.595 & 41.6 & 47.8 & 0.446 \\
\hline Hypercholesterolemia & 19.7 & 12.1 & 0.009 & 17.0 & 13.7 & 0.820 & 15.5 & 15.9 & 0.263 & 13.1 & 13.4 & 0.073 \\
\hline Diabetes & 13.8 & 10.5 & 0.731 & 11.6 & 16.9 & 0.433 & 10.0 & 14.4 & 0.584 & 13.6 & 10.8 & 0.404 \\
\hline Stroke & 2.7 & 1.6 & 0.930 & 1.8 & 3.2 & 0.828 & 3.0 & 1.5 & 0.714 & 2.3 & 3.2 & 0.776 \\
\hline Myocardial infarction & 11.2 & 8.9 & 0.267 & 10.1 & 9.7 & 0.897 & 10.5 & 11.4 & 0.824 & 9.5 & 7.6 & 0.265 \\
\hline Cancer & 1.6 & 4.8 & 0.239 & 2.2 & 2.4 & 0.738 & 4.5 & 0.8 & 0.205 & 1.8 & 4.5 & 0.387 \\
\hline Hearing impairment & 12.8 & 6.5 & 0.295 & 8.3 & 9.7 & 0.781 & 9.0 & 12.9 & 0.566 & 10.0 & 10.2 & 0.977 \\
\hline Cataract & 22.3 & 20.2 & 0.795 & 23.5 & 19.4 & 0.681 & 23.5 & 19.7 & 0.842 & 14.9 & 29.3 & 0.002 \\
\hline Joint inflammation & 10.1 & 12.9 & 0.510 & 9.8 & 14.5 & 0.414 & 11.5 & 14.4 & 0.265 & 14.0 & 8.3 & 0.393 \\
\hline Osteoporosis & 8.0 & 4.8 & 0.373 & 7.9 & 6.5 & 0.722 & 7.0 & 8.3 & 0.998 & 6.3 & 8.9 & 0.827 \\
\hline Body Mass Index in $\mathrm{kg} / \mathrm{m}^{2}, \%$ & & & 0.575 & & & 0.995 & & & 0.700 & & & 0.308 \\
\hline$<18.5$ & 6.4 & 6.5 & & 5.4 & 4.8 & & 5.5 & 6.1 & & 3.2 & 8.3 & \\
\hline$\geq 18.5$ and $<25.0$ & 68.6 & 62.9 & & 64.3 & 66.9 & & 64.5 & 65.2 & & 66.5 & 65.6 & \\
\hline$\geq 25.0$ & 25.0 & 30.7 & & 30.3 & 28.2 & & 30.0 & 28.8 & & 30.3 & 26.1 & \\
\hline Total score of the TMIG & $12.2(1.0) \uparrow$ & $12.6(0.8)$ & 0.007 & $12.5(0.8)$ & $12.2(1.0) \S$ & 0.006 & $12.5(0.9)$ & $12.3(1.0)$ & 0.304 & $12.5(0.9)$ & $12.3(0.9)$ & 0.241 \\
\hline IADL & $4.9(0.2)$ & $5.0(0.2)$ & 0.384 & $5.0(0.2)$ & $5.0(0.2)$ & 0.810 & $4.9(0.2)$ & $4.9(0.3)$ & 0.024 & $5.0(0.2)$ & $4.9(0.2)$ & 0.603 \\
\hline Intellectual activity & $3.6(0.7)$ & $3.6(0.8)$ & 0.786 & $3.7(0.7)$ & $3.5(0.8)$ & 0.136 & $3.7(0.7)$ & $3.6(0.8)$ & 0.497 & $3.7(0.7)$ & $3.6(0.7)$ & 0.297 \\
\hline Social role & $3.7(0.7) 9$ & $4.0(0.3)$ & $<.001$ & $3.9(0.3)$ & $3.7(0.6) \S$ & 0.007 & $3.8(0.4)$ & $3.8(0.5)$ & 0.461 & $3.8(0.5)$ & $3.8(0.5)$ & 0.451 \\
\hline
\end{tabular}

S.D., Standard Deviation; TMIG, the Tokyo Metropolitan Institute of Gerontology Index of Competence; IADL, instrumental activity of daily living; SDR, Social Desirability Response.

Each personality trait (scored on a scale of 0-12) was divided into four categories approximately equal in size, on the basis of the score in the population as a whole. Consequently, different personality traits has different cutoff scores.

aAnalysis of variance for continuous variable and chi-square test for categorical variables.

\$Statistical significance was defined as $P<0.05$ compared with quartile 1 (lowest trait score) by Tukey post-hoc test.

'Statistical significance was defined as $P<0.05$ compared with quartile 4 (highest trait score) by Tukey post-hoc test. 
Table 4. Logistic regression analysis of the association between health behavior and future risk for higher-level functional decline in the Ohasama Study, Japan, 1998-2005.

\begin{tabular}{|c|c|c|c|c|c|c|c|c|c|c|c|c|}
\hline \multirow[b]{2}{*}{$\begin{array}{l}\text { Personality } \\
\text { trait score }\end{array}$} & \multicolumn{3}{|c|}{ Extraversion } & \multicolumn{3}{|c|}{ Psychoticism } & \multicolumn{3}{|c|}{ Neuroticism } & \multicolumn{3}{|c|}{ Lie } \\
\hline & $\begin{array}{c}\text { No. of } \\
\text { cases } \\
\text { of decline } \\
(\%)\end{array}$ & $\begin{array}{l}\text { Multivariable OR } \\
\qquad(95 \% \mathrm{CI})^{\mathrm{a}}\end{array}$ & $P$ value & $\begin{array}{c}\text { No. of } \\
\text { cases } \\
\text { of decline } \\
(\%)\end{array}$ & $\begin{array}{c}\text { Multivariable OR } \\
\qquad(95 \% \mathrm{CI})^{\mathrm{a}}\end{array}$ & $P$ value & $\begin{array}{c}\text { No. of } \\
\text { cases } \\
\text { of decline } \\
(\%)\end{array}$ & $\begin{array}{l}\text { Multivariable OR } \\
\qquad(95 \% \mathrm{CI})^{\mathrm{a}}\end{array}$ & $P$ value & $\begin{array}{c}\text { No. of } \\
\text { cases } \\
\text { of decline } \\
(\%)\end{array}$ & $\begin{array}{l}\text { Multivariable OR } \\
\qquad(95 \% \mathrm{CI})^{\mathrm{a}}\end{array}$ & $P$ value \\
\hline \multicolumn{13}{|c|}{ Total score of the TMIG } \\
\hline $\mathrm{Q} 1^{\mathrm{b}}$ & $51(27.1)$ & $1.89(1.01-3.56)$ & 0.047 & $49(17.7)$ & 1.00 (Reference) & & $44(22.0)$ & 1.00 (Reference) & & $42(19.0)$ & 1.00 (Reference) & \\
\hline Q2 & $32(20.9)$ & $1.41(0.73-2.72)$ & 0.306 & $33(21.4)$ & $1.37(0.80-2.34)$ & 0.255 & $35(23.0)$ & $0.92(0.53-1.61)$ & 0.777 & $41(21.6)$ & $1.05(0.61-1.80)$ & 0.853 \\
\hline Q3 & $41(19.4)$ & $1.14(0.60-2.14)$ & 0.694 & $28(23.1)$ & $1.27(0.71-2.28)$ & 0.417 & $39(20.3)$ & $0.86(0.50-1.48)$ & 0.594 & $27(25.0)$ & $1.39(0.76-2.56)$ & 0.287 \\
\hline Q4 & $23(18.6)$ & 1.00 (Reference) & & $37(29.8)$ & $2.12(1.23-3.66)$ & 0.007 & $29(22.0)$ & $0.86(0.47-1.54)$ & 0.604 & $37(23.6)$ & $1.09(0.62-1.92)$ & 0.759 \\
\hline \multicolumn{2}{|c|}{ Continuous $^{\mathrm{c}}$} & $0.80(0.66-0.97)$ & 0.023 & & $1.25(1.06-1.49)$ & 0.012 & & $0.95(0.79-1.14)$ & 0.556 & & $1.05(0.88-1.26)$ & 0.590 \\
\hline \multicolumn{13}{|c|}{ Subscale of the TMIG } \\
\hline \multicolumn{13}{|l|}{ IADL } \\
\hline $\mathrm{Q} 1^{\mathrm{b}}$ & $44(23.4)$ & $1.75(0.89-3.41)$ & 0.103 & $46(16.6)$ & 1.00 (Reference) & & $32(16.0)$ & 1.00 (Reference) & & $40(18.1)$ & 1.00 (Reference) & \\
\hline Q2 & $28(18.3)$ & $1.40(0.70-2.81)$ & 0.342 & $28(18.2)$ & $1.14(0.65-2.00)$ & 0.648 & $27(17.8)$ & $0.99(0.54-1.84)$ & 0.981 & $31(16.3)$ & $0.68(0.39-1.21)$ & 0.192 \\
\hline Q3 & $31(14.7)$ & $0.84(0.42-1.65)$ & 0.606 & $24(19.8)$ & $1.09(0.59-2.00)$ & 0.786 & $34(17.7)$ & $1.25(0.69-2.25)$ & 0.461 & $19(17.6)$ & $0.78(0.40-1.51)$ & 0.462 \\
\hline Q4 & $20(16.1)$ & 1.00 (Reference) & & $25(20.2)$ & $1.37(0.76-2.48)$ & 0.293 & $30(22.7)$ & $1.52(0.82-2.82)$ & 0.181 & $33(21.0)$ & $0.87(0.49-1.56)$ & 0.642 \\
\hline \multicolumn{2}{|c|}{ Continuous $^{\mathrm{c}}$} & $0.78(0.63-0.96)$ & 0.019 & & $1.10(0.91-1.32)$ & 0.341 & & $1.16(0.95-1.41)$ & 0.147 & & $0.97(0.80-1.17)$ & 0.730 \\
\hline \multicolumn{13}{|c|}{ Intellectual activity } \\
\hline $\mathrm{Q1}^{\mathrm{b}}$ & $17(9.0)$ & $0.88(0.38-2.03)$ & 0.762 & $20(7.2)$ & 1.00 (Reference) & & $18(9.0)$ & 1.00 (Reference) & & $14(6.3)$ & 1.00 (Reference) & \\
\hline Q2 & $11(7.2)$ & $0.82(0.34-2.01)$ & 0.670 & $12(7.8)$ & $1.09(0.50-2.35)$ & 0.836 & $14(9.2)$ & $0.87(0.40-1.89)$ & 0.720 & $21(11.1)$ & $1.77(0.83-3.78)$ & 0.138 \\
\hline Q3 & $20(9.5)$ & $0.93(0.42-2.06)$ & 0.855 & $15(12.4)$ & $1.58(0.74-3.39)$ & 0.236 & $20(10.4)$ & $1.16(0.56-2.40)$ & 0.692 & $8(7.4)$ & $1.26(0.49-3.26)$ & 0.635 \\
\hline Q4 & $13(10.5)$ & 1.00 (Reference) & & $14(11.3)$ & $1.46(0.68-3.11)$ & 0.332 & $9(6.8)$ & $0.66(0.27-1.60)$ & 0.356 & $18(11.5)$ & $1.92(0.87-4.26)$ & 0.106 \\
\hline \multicolumn{2}{|c|}{ Continuous $^{\mathrm{e}}$} & $1.05(0.81-1.36)$ & 0.723 & & $1.16(0.91-1.47)$ & 0.222 & & $0.93(0.72-1.21)$ & 0.595 & & $1.18(0.92-1.52)$ & 0.185 \\
\hline \multicolumn{13}{|c|}{ Social role } \\
\hline $\mathrm{Q1}^{\mathrm{b}}$ & $28(14.9)$ & $4.81(1.77-13.03)$ & 0.002 & $26(9.4)$ & 1.00 (Reference) & & $20(10.0)$ & 1.00 (Reference) & & $19(8.6)$ & 1.00 (Reference) & \\
\hline Q2 & $14(9.2)$ & $2.89(1.00-8.36)$ & 0.050 & $11(7.1)$ & $0.70(0.32-1.51)$ & 0.360 & $12(7.9)$ & $0.68(0.30-1.51)$ & 0.342 & $14(7.4)$ & $0.63(0.29-1.37)$ & 0.241 \\
\hline Q3 & $16(7.6)$ & $4.81(1.77-13.03)$ & 0.278 & $13(10.7)$ & $1.03(0.48-2.20)$ & 0.945 & $15(7.8)$ & $0.79(0.37-1.70)$ & 0.551 & $12(11.1)$ & $1.18(0.52-2.67)$ & 0.692 \\
\hline Q4 & $6(4.8)$ & 1.00 (Reference) & & $14(11.3)$ & $1.20(0.58-2.51)$ & 0.625 & 17 (12.9) & $1.37(0.65-2.91)$ & 0.409 & $19(12.1)$ & $1.13(0.54-2.37)$ & 0.740 \\
\hline \multicolumn{2}{|c|}{ Continuous $^{\mathrm{c}}$} & $0.60(0.45-0.79)$ & $<.001$ & & $1.06(0.84-1.35)$ & 0.612 & & $1.10(0.85-1.42)$ & 0.460 & & $1.09(0.86-1.40)$ & 0.468 \\
\hline
\end{tabular}

OR, Odds Ratio; CI, Confidence Interval; TMIG, the Tokyo Metropolitan Institute of Gerontology Index of Competence; IADL, instrumental activity of daily living.

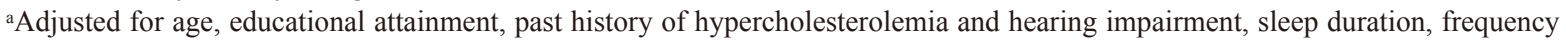
of eating out, and BMI.

${ }^{\mathrm{b}} \mathrm{Q} 1-\mathrm{Q} 4$ indicated the quartile 1 (lowest) to quartile 4 (highest) of each personality score. A multiple logistic regression model by quartiles for each personality trait was conducted.

${ }^{\mathrm{c} A}$ multiple linear regression model for continuous analysis of each personality trait was conducted.

values $\leq 0.10$. On multiple logistic regression analysis, lowest levels of extraversion (i.e., introversion) and the highest quartile of psychoticism were associated with the risk of future higher-level functional decline based on total TMIG scores [lowest quartile of extraversion: odds ratio (95\% confidence interval) 1.89 (1.01-3.56); higher quartiles of psychoticism: $2.12(1.23-3.66)]$. In the subscale analysis, the increased risk of future higher-level functional decline in those with high introversion scores was also observed for the social role subscale [4.81 (1.77-13.03)]; however, other personality traits, i.e., neuroticism and lie, were not associated with any of the subscales. These significant associations were also observed in the linear regression models. Increasing scores for extraversion and psychoticism were inversely and positively associated with the decline in the total score of the TMIG [extraversion: 0.80 (0.66-0.97); psychoticism: 1.25 (1.06-1.49)]. An increased score of extraversion was inversely related to IADL and social role subscale [IADL: $0.79(0.63-0.96)$; social role:
$0.60(0.45-0.79)]$.

When we restricted our analysis to participants who reported a perfect score at baseline, our significant results of introversion on the social role and psychoticism in the total TMIG score were similar [the lowest quartile of extraversion in the social role was $5.73(1.63-20.10), P=0.006$, and the highest quartile of psychoticism was 3.35 (1.616.97), $P=0.001]$, but the association with the lowest quartile of extraversion in the total TMIG score was not significant [2.09 (0.95-4.57), $P=0.066]$ although these variables were still associated in the linear regression model $[0.76$ (0.59-0.98), $P=0.036]$ (data not shown). In addition, we analyzed the relationship of TMIG decline, including frequency of exercise as a confounding variable, which is an important factor that can affect IADL in the elderly, or included factors that indicated significant differences for each personality category. However, additional adjustments that included these factors did not alter our results (data not shown). 
Further analyses were conducted to assess the association between overall personality traits and TMIG subscale scores regarding decline in higher-level function. These analyses found a similar pattern of results in risks [in the total TMIG score, highest quartile of psychoticism: 2.01 (1.14-3.55); lowest quartile of extraversion: 1.88 (0.993.56 ); and the social role subscale, lowest quartile of extraversion: 4.96 (1.80-13.72)]. Regarding joint classification of quartiles of personality traits and the risk of future higher-level functional decline, no differences were observed between healthy and unhealthy lifestyle and behavioral factors at baseline. For example, we found similar risks of psychoticism between drinkers and never or exdrinkers [3.04 (1.20-7.68) and 2.17 (1.03-4.52), respectively], and exercise $\geq 1 \mathrm{~h} /$ week and rarely or never [3.79 (1.11-37.93) and 1.95 (1.04-3.64), respectively]. No significant interactions were observed between each factor $(P>$ 0.10 for all factors).

\section{Discussion}

The current study indicated that higher levels of psychoticism were associated with poorer higher-level functioning, whereas the higher levels of extraversion were associated with reduced risk of higher-level functional decline during a 7-year period among non-disabled, Japanese, community-dwelling older adults.

Our study has several strengths. First, it is the first study to examine whether personality traits can predict poorer higher-level functioning measured by TMIG. Because of the prospective design and exclusion of subjects that exhibited functional deterioration due to illness at baseline, sample size with lifestyle-related behavioral change was minimized. In addition, we included extensive controls for potential cofound variables of higher-level functional decline, e.g., age, educational attainment, past history of hypercholesterolemia and hearing impairment, sleep duration, frequency of eating out, and BMI. When we stratified the analysis by healthy and unhealthy lifestyle and behavioral factors, no differences were observed in subjects with no decline and decline in higher-level functional capacity. Therefore, we believe that it is unlikely that lifestyle and behavioral factors, which are determined by personality traits at baseline, affected the future higher-level functional decline. Finally, we used the validated Japanese version of Eysenck's personality questionnaire developed by Eysenck (Eysenck et al. 1985; Hosokawa and Ohyama 1993).

Until now, there were few studies to examine the association between personality and functional decline (Duberstein et al. 2003). Furthermore, previous studies have been mainly cross-sectional and have focused on functional limitations, disability, and lower ADL scores as outcomes, rather than early-stage functional decline. However, results from these cross-sectional studies were inconsistent with our findings, showing no apparent association between extraversion and functional disability (Kempen et al. 1999a, b; Jang et al. 2003). Only one previous prospective study of the relationship between higher levels of extraversion and disability was consistent with our findings (Krueger et al. 2006), but no previous studies have investigated the association between psychoticism and functional decline.

Lower levels of extraversion were statistically associated with future risk of higher-level functional decline, particularly decreased social role. Our results were similar to those of a previous study that examined disability (Krueger et al. 2006), but not in early-stage functional decline, in the elderly. Furthermore, no previous studies have examined these associations in Asian countries. Low social role is defined by decreased levels of social contact and interest and occurs with age prior to IADL decline (Ishizaki et al. 2000). Because levels of social activity were inversely related to risk of functional decline (Landi et al. 2004), our results suggest that people with a high level of extraversion are more likely to maintain higher-level functional capacity than those with low levels of extraversion.

Psychoticism is characterized by tough-mindedness, aggressiveness, coldness, and egocentricity. It is known that individuals with higher levels of psychoticism tend to decide and act by themselves. In the present study, those with higher levels of psychoticism were likely to have poor health behaviors such as current smokers, heavier drinkers, and those having higher frequency of skipping breakfast. Our previous study revealed that these unhealthier lifestyles were also significantly and independently related to future functional decline (Tsubota-Utsugi et al. 2011). However, we cannot control unmeasured or residual confounders. For instance, individuals with higher levels of psychoticism might engage in poor health behaviors that contribute to future declines in higher-level functions. Further prospective studies with more detailed information regarding lifestyle-associated factors are needed to help researchers develop an early understanding of how personality traits are related to future functional deterioration.

In the present study, we did not find any association between the Lie personality scores and subsequent functional decline. The Lie scales were originally introduced into personality measurements to detect the tendency of some respondents to 'fake good' or show socially desirable characteristics (Eysenck et al. 1985). However, the notion of the Lie scale has not remained so simple, and indeed the Lie scale is believed to measure of a tendency to conform (Hosokawa and Ohyama 1993, Arai et al. 1997). Because the Lie scale indicates interpersonal values and behavioral diligence, it may more strongly be associated with the assessment for health behaviors such as smoking and alcohol use rather than as an indicator of actual functional decline.

Past studies suggested that neuroticism affects biological or physiological mechanisms and may affect certain clinical outcomes and mortality (Wilson et al. 2005; Shipley et al. 2007), but recent studies revealed that specified personality traits do not influence mortality (Iwasa et al. 2008; Andre et al. 2014). According to the hierarchical model of 
functional and behavioral competence (Lawton and Brody 1969; Lawton 1972), higher-level functional decline consists of the complex abilities required to maintain functional capacity at early stages - IADLs, intellectual activity, and social role performance - which are not diagnosed in certain diseases. Higher levels of neuroticism may be associated with depressive symptoms, and thus, with clinical outcomes and mortality, rather than early-stage functional decline.

Several limitations of the present study need to be discussed. First, information about demographic and lifestyle characteristics was obtained only at baseline. Considering the difficulties that older adults face in making lifestyle changes, it is unlikely that positive lifestyle changes occurred, whereas some participants likely experienced deterioration in their functional capacity due to illness (the exclusion cases). Moreover, participants had to be sufficiently independent to participate in this study because only those who could complete a self-administered questionnaire at baseline could participate in the follow-up measurement, thus, we believe participants who forced to lifestyle changes were scarce.

Next our study's main focus was the relationship between social, psychological, and lifestyle characteristics and the risk of functional decline; however, we did not consider the risk of cognitive impairment. A previous study reported that disability and cognitive impairment exhibited a similar pattern of increasing frequency with age (Alonso Serra et al. 1995), and subjects with low cognitive performance were at higher risk of functional impairment in subsequent years (Barberger-Gateau and Fabrigoule 1997). Another study also indicated that cognitive impairment is a risk factor for additional functional decline among patients with or without ADL dependence at baseline (Mehta et al. 2002). Because there is an interaction between functional decline and cognitive impairment, further prospective studies would improve our understanding of specifically how cognitive impairment is related to the progression of functional decline.

In our present study, we used difference scores to determine whether there were increases or declines in functioning. Using difference scores as a way of measuring change and dealing with hierarchically nested data may lead to several biases and ignores between- and withingroup variations (Cook and Campbell 1979; Kreft and Leeuw 1998). However, this was a prospective study with healthy elderly participants. Furthermore, our additional analysis using only participants who reported a perfect score at baseline did not find any differences in results. A confirmatory result for psychoticism was observed when we performed the analysis based on the reliable change index ( $p=0.011$; Jacobson and Truax 1991), although the index should be applicable to a variable with normal distribution; the TMIG score in the present study was unbalanced because we had limited our study population to nondisabled elderly at baseline. Whereas, we cannot adapt the current method in our future studies, i.e., measurements on more than 3 occasions. Future analysis using multilevel modeling and other modeling methods will be able to solve these problems and may give us a better understanding of functional changes.

The possibility of selection bias must also be considered when generalizing the present findings because only $62.9 \%$ of those eligible to participate in the study completely answered the short EPQ-R. Because the mean age of EPQ-R responders was slightly lower than that of those who were excluded, we hypothesized that this difference was related to difficulty in filling out the EPQ-R. Because we excluded those who exhibited functional decline at baseline and who did not return completed questionnaires, it is possible that healthy people were more likely to be followed up. Even though previous studies have reported that certain personality traits may be independently associated with a future risk of functional decline, such evidence is less frequently reported in Asian populations, and marked differences such as culture, behaviors, and health outcomes also exist in the epidemiology of functional decline among Japanese and Western populations. Thus, personality characteristics may be different as a result of differences in social and cultural backgrounds. Further studies that examine different ethnic and cultural populations are needed to confirm the generalizability of our findings and to clarify similarities and differences among patients in different countries.

In conclusion, the present analysis of older adults indicated a statistically significant association of the personality traits of higher psychoticism and lower extraversion with a risk of future functional decline. Although the mechanism of functional decline influenced by personality remains unclear, our results suggest that a better understanding of personality traits would be useful for the early detection and prevention for elderly at a high risk of functional decline. Because personality traits were associated with other clinical health outcomes, public health programs to detect those at a high risk might contribute to preventing future health outcomes, possibly leading to prevention of ADL deterioration.

\section{Acknowledgments}

This study was supported by Grants for Scientific Research (23790718, 23249036, 23390171, 24390084, 24591060, 24790654, 25253059, 25461083, 25461205, 25860156, 26282200, and 26860093) from the Ministry of Education, Culture, Sports, Science, and Technology, Japan; a Grant-in-Aid from the Japan Society for the Promotion of Science (JSPS) fellows (25.7756, 25.9328 and 26.857); the Japan Arteriosclerosis Prevention Fund an Intramural Research Fund; (22-4-5) for Cardiovascular Diseases of National Cerebral and Cardiovascular Center; and a Health Labor Sciences Research Grant (H26-Junkankitou [Seisaku]-Ippan-001) from the Ministry of Health, Labor, and Welfare.

\section{Conflict of Interest}

The authors declare no conflict of interest. 


\section{References}

Almada, S.J., Zonderman, A.B., Shekelle, R.B., Dyer, A.R., Daviglus, M.L., Costa, P.T. Jr. \& Stamler, J. (1991) Neuroticism and cynicism and risk of death in middle-aged men: the Western Electric Study. Psychosom. Med., 53, 165-175.

Alonso Serra, M.L., Conde, J.G., De Andino, R.M. \& Mendoza, M.M. (1995) Prevalence of cognitive and functional impairment in an elderly Puerto Rican population. PR Health Sci. J., $14,279-283$

Amorim-Cruz, J.A., Haveman-Nies, A., Schlettwein-Gsell, D. \& De Henauw, S. (2002) Gender, cohort and geographical differences in 10-year mortality in elderly people living in 12 European towns. J. Nutr. Health Aging, 6, 269-274.

Andre, M., Billstedt, E., Bengtsson, C., Hallstrom, T., Lissner, L., Skoog, I., Sundh, V., Waern, M. \& Bjorkelund, C. (2014) Personality in women and associations with mortality: a 40-year follow-up in the Population Study of Women in Gothenburg. BMC Womens Health, 14, 61.

Arai, Y., Hosokawa, T., Fukao, A., Izumi, Y. \& Hisamichi, S. (1997) Smoking behaviour and personality: a populationbased study in Japan. Addiction, 92, 1023-1033.

Barberger-Gateau, P. \& Fabrigoule, C. (1997) Disability and cognitive impairment in the elderly. Disabil. Rehabil., 19, 175-193.

Cook, T.D. \& Campbell, D.T. (1979) Quasi-experimentation: design and analysis issues for field settings, Houghton Mifflin, Boston.

Duberstein, P.R., Sorensen, S., Lyness, J.M., King, D.A., Conwell, Y., Seidlitz, L. \& Caine, E.D. (2003) Personality is associated with perceived health and functional status in older primary care patients. Psychol. Aging, 18, 25-37.

Eysenck, S.B.G., Eysenck, H.J. \& Barrett, P. (1985) A revised version of the psychoticism scale. Person. Individ. Diff., 6, 21-29.

Fujiwara, Y., Shinkai, S., Amano, H., Watanabe, S., Kumagai, S., Takabayashi, K., Yoshida, H., Hoshi, T., Tanaka, M., Morita, M. \& Haga, H. (2003a) Test-retest variation in the Tokyo Metropolitan Institute of Gerontology Index of Competence in community-dwelling older people independent in daily living toward individual assessment of functional capacity. Nippon Koshu Eisei Zasshi, 50, 360-367.

Fujiwara, Y., Shinkai, S., Kumagai, S., Amano, H., Yoshida, Y., Yoshida, H., Kim, H., Suzuki, T., Ishizaki, T., Haga, H., Watanabe, S. \& Shibata, H. (2003b) Longitudinal changes in higher-level functional capacity of an older population living in a Japanese urban community. Arch. Gerontol. Geriatr., 36, 141-153.

Fujiwara, Y., Shinkai, S., Kumagai, S., Amano, H., Yoshida, Y., Yoshida, H., Kim, H., Suzuki, T., Ishizaki, T., Watanabe, S., Haga, H. \& Shibata, H. (2003c) Changes in TMIG-Index of Competence by subscale in Japanese urban and rural community older populations: Six years prospective study. Geriatr. Gerontol. Int., 3, S63-S68.

Fujiwara, Y., Shinkai, S., Watanabe, S., Kumagai, S., Suzuki, T., Shibata, H., Hoshi, T. \& Kita, T. (2000) Effects of chronic medical conditions on changes in the higher level of functional capacity in Japanese older community residents. J. Aging Phys. Act., 8, 148-161.

Hampson, S.E., Goldberg, L.R., Vogt, T.M. \& Dubanoski, J.P. (2007) Mechanisms by which childhood personality traits influence adult health status: educational attainment and healthy behaviors. Health Psychol., 26, 121-125.

Hosokawa, T. \& Ohyama, M. (1993) Reliability and validity of a Japanese version of the short-form Eysenck questionnaire : revised. Psychol. Rep., 72, 823-832.

Hozawa, A., Ohkubo, T., Obara, T., Metoki, H., Kikuya, M., Asayama, K., Totsune, K., Hashimoto, J., Hoshi, H., Arai, Y.,
Satoh, H., Hosokawa, T. \& Imai, Y. (2006) Introversion associated with large differences between screening blood pressure and home blood pressure measurement: the Ohasama study. $J$. Hypertens., 24, 2183-2189.

Imai, E., Tsubota-Utsugi, M., Kikuya, M., Satoh, M., Inoue, R., Hosaka, M., Metoki, H., Fukushima, N., Kurimoto, A., Hirose, T., Asayama, K., Imai, Y. \& Ohkubo, T. (2014) Animal protein intake is associated with higher-level functional capacity in elderly adults: the Ohasama study. J. Am. Geriatr. Soc., 62, 426-434

Ishizaki, T., Watanabe, S., Suzuki, T., Shibata, H. \& Haga, H. (2000) Predictors for functional decline among nondisabled older Japanese living in a community during a 3-year followup. J. Am. Geriatr. Soc., 48, 1424-1429.

Iwasa, H., Masui, Y., Gondo, Y., Inagaki, H., Kawaai, C. \& Suzuki, T. (2008) Personality and all-cause mortality among older adults dwelling in a Japanese community: a five-year population-based prospective cohort study. Am. J. Geriatr. Psychiatry, 16, 399-405.

Jacobson, N.S. \& Truax, P. (1991) Clinical significance: a statistical approach to defining meaningful change in psychotherapy research. J. Consult. Clin. Psychol., 59, 12-19.

Jang, Y., Haley, W.E., Mortimer, J.A. \& Small, B.J. (2003) Moderating effects of psychosocial attributes on the association between risk factors and disability in later life. Aging Ment. Health, 7, 163-170.

Kaneki, M., Hodges, S.J., Hosoi, T., Fujiwara, S., Lyons, A., Crean, S.J., Ishida, N., Nakagawa, M., Takechi, M., Sano, Y., Mizuno, Y., Hoshino, S., Miyao, M., Inoue, S., Horiki, K., et al. (2001) Japanese fermented soybean food as the major determinant of the large geographic difference in circulating levels of vitamin $\mathrm{K}_{2}$ : possible implications for hip-fracture risk. Nutrition, 17, 315-321.

Kempen, G.I., van Heuvelen, M.J., van Sonderen, E., van den Brink, R.H., Kooijman, A.C. \& Ormel, J. (1999a) The relationship of functional limitations to disability and the moderating effects of psychological attributes in communitydwelling older persons. Soc. Sci. Med., 48, 1161-1172.

Kempen, G.I., van Sonderen, E. \& Ormel, J. (1999b) The impact of psychological attributes on changes in disability among low-functioning older persons. J. Gerontol. B Psychol. Sci. Soc. Sci., 54, 23-29.

Koyano, W., Hashimoto, M., Fukawa, T., Shibata, H. \& Gunji, A. (1993) Functional capacity of the elderly: measurement by the TMIG Index of Competence. Jpn. J. Public Health, 40, 468-474.

Koyano, W. \& Shibata, H. (1992) Cross-validation of the TMIG Index of Competence: Invariability of factor structure and predictive validity. Japanese Journal of Gerontology (Ronen Shakai Kagaku), 14, 34-42.

Koyano, W., Shibata, H., Nakazato, K., Haga, H. \& Suyama, Y. (1987) Measurement of competence in the elderly living at home: development of an index of competence. Jpn. J. Public Health, 34, 109-114.

Koyano, W., Shibata, H., Nakazato, K., Haga, H. \& Suyama, Y. (1991) Measurement of competence: reliability and validity of the TMIG Index of Competence. Arch. Gerontol. Geriatr., 13, 103-116.

Kreft, I. \& Leeuw, J.D. (1998) Introducing Multilevel Modeling, SAGE Publications Ltd., London.

Krueger, K.R., Wilson, R.S., Shah, R.C., Tang, Y. \& Bennett, D.A. (2006) Personality and incident disability in older persons. Age Ageing, 35, 428-433.

Kwon, J., Suzuki, T., Kumagai, S., Shinkai, S. \& Yukawa, H. (2006) Risk factors for dietary variety decline among Japanese elderly in a rural community: a 8-year follow-up study from TMIG-LISA. Eur. J. Clin. Nutr., 60, 305-311.

Landi, F., Cesari, M., Onder, G., Lattanzio, F., Gravina, E.M. \& Bernabei, R. (2004) Physical activity and mortality in frail, 
community-living elderly patients. J. Gerontol. A Biol. Sci. Med. Sci., 59, 833-837.

Lawton, M.P. \& Brody, E.M. (1969) Assessment of older people: self-maintaining and instrumental activities of daily living. Gerontologist, 9, 179-186.

Lawton, M. (1972) Assessing the competence of older people, Human Sciences Press, New York.

Mehta, K.M., Yaffe, K. \& Covinsky, K.E. (2002) Cognitive impairment, depressive symptoms, and functional decline in older people. J. Am. Geriatr. Soc., 50, 1045-1050.

Ministry of Health, Labour and Welfare (2005) Health and Welfare Statistics Association. Journal of Health and Welfare Statistics (Vol. 52).

Ministry of Health, Labour and Welfare (2008) Statistical abstracts on health and welfare in Japan 2007. Statistics and Information Department. Ministry of Health, Labour and Welfare, Tokyo, Japan.

Ohkubo, T., Asayama, K. \& Imai, Y. (2006) The value of selfmeasured home blood pressure in predicting stroke. Expert Rev. Neurother., 6, 163-173.

Shipley, B.A., Weiss, A., Der, G., Taylor, M.D. \& Deary, I.J. (2007) Neuroticism, extraversion, and mortality in the UK Health and Lifestyle Survey: a 21-year prospective cohort study. Psychosom. Med., 69, 923-931.

Stewart, A.L., Greenfield, S., Hays, R.D., Wells, K., Rogers, W.H., Berry, S.D., McGlynn, E.A. \& Ware, J.E. Jr. (1989) Functional status and well-being of patients with chronic conditions. Results from the Medical Outcomes Study. JAMA, 262,
907-913.

Stewart, A.L., Hays, R.D. \& Ware, J.E. Jr. (1988) The MOS shortform general health survey. Reliability and validity in a patient population. Med. Care, 26, 724-735.

Tinetti, M.E., Inouye, S.K., Gill, T.M. \& Doucette, J.T. (1995) Shared risk factors for falls, incontinence, and functional dependence. Unifying the approach to geriatric syndromes. JAMA, 273, 1348-1353.

Tsubota-Utsugi, M., Ito-Sato, R., Ohkubo, T., Kikuya, M., Asayama, K., Metoki, H., Fukushima, N., Kurimoto, A., Tsubono, Y. \& Imai, Y. (2011) Health behaviors as predictors for declines in higher-level functional capacity in older adults: the Ohasama study. J. Am. Geriatr. Soc., 59, 1993-2000.

Tsuji, I., Imai, Y., Nagai, K., Ohkubo, T., Watanabe, N., Minami, N., Itoh, O., Bando, T., Sakuma, M., Fukao, A., Satoh, H., Hisamichi, S. \& Abe, K. (1997) Proposal of reference values for home blood pressure measurement: prognostic criteria based on a prospective observation of the general population in Ohasama, Japan. Am. J. Hypertens., 10, 409-418.

Tsuji, I., Kuwahara, A., Nishino, Y., Ohkubo, T., Sasaki, A. \& Hisamichi, S. (1999) Medical cost for disability: a longitudinal observation of national health insurance beneficiaries in Japan. J. Am. Geriatr. Soc., 47, 470-476.

Wilson, R.S., Krueger, K.R., Gu, L., Bienias, J.L., Mendes de Leon, C.F. \& Evans, D.A. (2005) Neuroticism, extraversion, and mortality in a defined population of older persons. Psychosom. Med., 67, 841-845. 